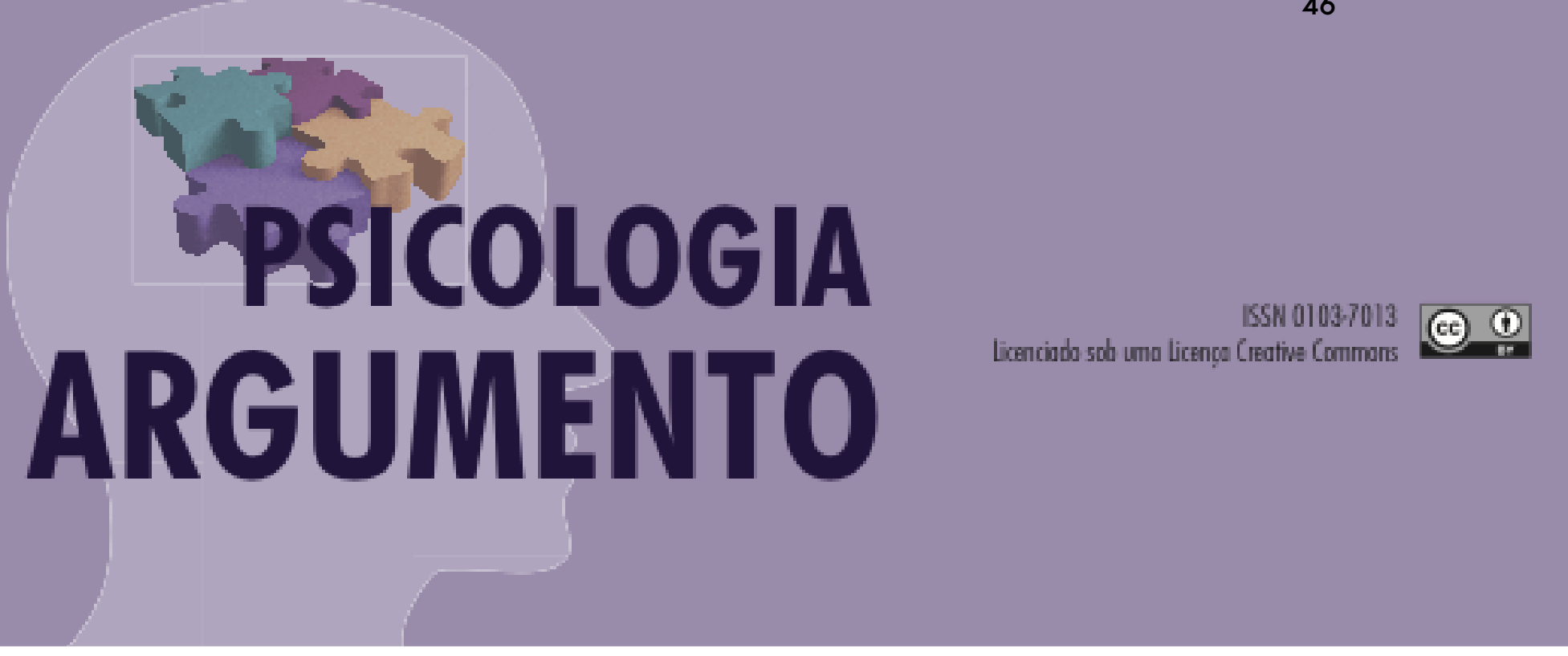

doi: http://dx.doi.org/10.7213/psicolargum.38.99.AO03

\title{
A articulação de múltiplas atividades por mulheres trabalhadoras:
}

\section{significados e emoções}

The meaning and emotions of working women against the join of multiple activities

El significado y las emociones de mujeres trabajadores frente a la articulación de

múltiples actividades

Silvia Rocio da Silva

Mestre em Psicologia, Universidade Tuiuti do Paraná.

Orcid: https://orcid.org/0000-0002-6097-3491

Denise de Camargo

Docente do Mestrado em Psicologia, Universidade Tuiuti do Paraná.

Orcid: https://orcid.org/0000-0001-9092-9988

\section{Resumo}

Este artigo apresenta a compreensão do significado e as emoções que as mulheres ouvidas expressaram sobre a articulação de suas atividades pessoais, profissionais e familiares. Caracteriza-se como uma pesquisa qualitativa, descritiva exploratória, e os dados foram produzidos por meio de entrevistas abertas e ensaios fotográficos, utilizados como mediadores, gerados por quatro mulheres, profissionais de nível superior e residentes em Curitiba. Os dados 
foram analisados com base na Teoria da Subjetividade, na perspectiva da Psicologia HistóricoCultural. A análise dos dados permitiu a identificação das categorias de sentido subjetivo de maternidade, de trabalho, de articular atividades e de significado da família no processo de articular atividades e subjetividade feminina. O estudo revelou dimensões naturalizantes implicadas na vida das mulheres pesquisadas; a rede de significação constituída pela articulação de atividades profissionais, pessoais e familiares dessas mulheres indica a presença de sentidos subjetivos de ambivalência, gerando dificuldade, tensão e sofrimento.

Palavras-chave: mulheres; trabalho; subjetividade; emoções.

\begin{abstract}
This article aims to understand the meaning and the emotions that women express on the timing of their personal activities, work and family. The data were collected through open interviews and photographic essays produced by four women, and analyzed based on the Theory of Subjectivity, from the perspective of Historical-Cultural Psychology. Data analysis allowed the identification of categories: subjective sense of motherhood, subjective sense of work, subjective sense of articulating activities, meaning of family in the process of articulating activities and female subjectivity. The study revealed naturalizing dimensions involved in the life of the women surveyed; the network of meaning constituted by the articulation of professional, personal and family activities of these women indicates the presence of subjective meanings of ambivalence, generating difficulty and suffering.
\end{abstract}

Keywords: women; labour; subjectivity; emotions.

\title{
Resumen
}

Este artículo pretende compreender el significado y las emociones que las mujeres expresan sobre la articulación de sus atividades personales profesional y familiar. Los datos fueron recolectados a través de entrevistas abiertas y ensayos fotográficos producidos por cuatro mujeres y analizados con base em la Teoría de la Subjetividad, em la perspectiva de la Psicología Histórico-Cultural. El análisis de los datos permitió la identificación de categorías: sentido subjetivo de maternidad, de trabajo subjetivo, de actividades articuladoras, significado de la família em el proceso de articulación de actividades y subjetividade femenina. El estúdio reveló dimensiones naturalizadoras involucradas em las vidas de las mujeres encuestadas; La red de significados constituida por la articulación de atividades profesionales, personales y familiares de essas mujeres indica la presencia de significados subjetivos de ambivalencia, generando dificultad y sufrimiento.

Palabras clave: mujeres; trabajo; subjetividad; emociones.

\section{Introdução}

Este artigo analisa a forma como as mulheres significam as atividades que desempenham na sociedade, identificando as emoções que são vivenciadas no processo de articulação dessas atividades. Apresenta uma pesquisa sobre a compreensão da articulação de diferentes atividades realizadas por mulheres, utilizando os pressupostos teóricos da Teoria da Subjetividade na perspectiva da psicologia histórico-cultural 
(Vygotsky, 1991; González Rey, 2003). Na subjetividade, o sentido expressa as emoções relacionadas aos significados e necessidades que vão se desenvolvendo dialeticamente no decorrer da história do sujeito, por meio de processos sociais.

O artigo é um recorte da dissertação de mestrado "Estudo sobre o significado e as emoções de mulheres trabalhadoras frente à articulação de múltiplas atividades". A metodologia da pesquisa foi inspirada no trabalho de Bosco (2009). O elemento central deste estudo é a análise de como a dificuldade de articular atividades profissionais, familiares e pessoais afeta diretamente as mulheres, suas famílias e indiretamente o mercado de trabalho, evidenciando desigualdades, ambivalências, contradições e ideologias.

A compreensão dos contextos sociais nos quais se desenvolvem as atividades das mulheres estudadas foi considerada, posto que as mulheres desenvolvem atividades profissionais em um mundo globalizado, cujo modelo profissional exige horas e mais horas de trabalho. Em uma sociedade na qual as novas tecnologias tornam a fronteira trabalho-família cada vez mais próxima, um fator importante a ser considerado é a capacidade que a pessoa nesse contexto desenvolve de distribuir seu tempo entre as diversas esferas de sua vida.

A categoria atividade deve ser entendida como determinada e definida pela forma como a sociedade se organiza para o trabalho. Leontiev (1978), autor que deu continuidade aos estudos de Vygotsky (1994) acerca da atividade humana, enfatizou o caráter coletivo dessa categoria. A estrutura da atividade é constituída pelas necessidades humanas, seus anseios e motivos. Nessa perspectiva, as ferramentas medeiam a expressão entre os sujeitos e sua relação com os elementos simbólicos (objetos e os signos). Assim, em uma contínua interação dialética, por meio da atividade, o sujeito modifica o mundo ao mesmo tempo em que é afetado por essa realidade (Leontiev, 1978; Bulgacov, Camargo, Canopf, Matos \& Zdepeski, 2014).

A partir da concepção de sujeito como um ser ativo e atuante na construção de si mesmo e da sociedade, compreende-se a mulher enquanto sujeito, que se constitui por meio da história e da cultura. De acordo com essa concepção, optou-se pela utilização da Teoria da Subjetividade de González Rey (2003), por apresentar uma subjetividade constantemente produzida e dialeticamente manifesta entre os âmbitos social e individual, 
sendo o individual representado por um sujeito implicado no processo de suas práticas, reflexões e produção de sentidos subjetivos. A subjetividade individual, dentro desse contexto, representa as formas de organização subjetiva que ocorrem nas histórias singulares dos sujeitos (González Rey, 2003).

O estudo da articulação dos diversos papéis femininos na sociedade constitui um exercício intelectual, permeado por sentimentos que se modificam conforme a história da mulher é relembrada. Sobretudo na segunda metade do século XX, muitas mudanças significativas ocorreram em relação à situação das mulheres, destacando-se os direitos legais adquiridos, inserção no espaço público e as mudanças na esfera privada que resultaram em maior autonomia nas escolhas afetivas.

Mudanças demográficas, culturais e sociais influenciaram a entrada maciça e consistente das mulheres no mercado de trabalho. A renda da mulher hoje não é mais secundária, contribuindo de forma importante na composição das receitas das famílias. Dados do Instituto Brasileiro de Geografia e Estatística - IBGE (2012) apontam que $46,1 \%$ das mulheres brasileiras são economicamente ativas, produzem para o País e integram o sistema produtivo. Em relação à formação acadêmica, segundo o Centro de Gestão e Estudos Estratégicos - CGEE (2012), o número de mulheres com mestrado no Brasil é maior que o número de homens com a mesma titulação, representando 53,5\% dos mestres, enquanto que os homens possuem 46,5\%. A inserção da mulher no mercado de trabalho, no entanto, não foi seguida de igualdade salarial A remuneração média da mulher é $28 \%$ menor que a dos homens.

O ranking "Abismo de Gênero", do Fórum Econômico Mundial (World EconomicForum, 2014), avalia 142 países em quatro dimensões principais: participação econômica, educação, capacitação política e saúde e sobrevivência. De acordo com esse ranking, em 2014, o Brasil ocupa a 71 a colocação; considerando somente a América Latina, o Brasil estava na $15^{\mathrm{a}}$ posição, dentre um total de 25 países. Dessa forma, evidencia-se que, apesar de o Brasil investir na educação, não conseguiu romper barreiras para a mulher progredir no mercado de trabalho.

A mulher participa de diversos espaços sociais, nos quais desenvolve suas diferentes atividades e produz múltiplos sentidos, constituindo sua subjetividade. Para González Rey (2003), a subjetividade não é delimitada apenas a nível individual, mas é 
essencialmente construída em um contexto social. Para o autor, "a subjetividade é um sistema complexo que tem dois espaços de constituição permanente e inter-relacionada: o individual e o social, que se constituem de forma recíproca, e ao mesmo tempo, cada um é constituído pelo outro" (González Rey, 2012, p. 145).O conceito de subjetividade social permite compreender a dimensão subjetiva dos diferentes processos e instituições sociais, assim como da rede complexa do social nos diferentes contextos em que ela se organiza através da história.

González Rey (2012) enfatiza a necessidade de produção de conhecimento sobre as configurações subjetivas que caracterizam a sociedade e os espaços sociais concretos. Nesse sentido, a utilização desse arcabouço de reflexão teórico-prático contribui para a realização de uma análise que vá além da realidade aparente da mulher contemporânea, no que diz respeito à articulação de diferentes atividades desempenhadas, vislumbrando a realidade concreta em seus diversos e contraditórios aspectos.

Neste estudo, destaca-se a importância do conceito de emoção na articulação das múltiplas atividades que as mulheres desempenham na sociedade ocidental na contemporaneidade. Camargo (1997, p. 212) conceitua emoção "como um sistema motivacional que pode ser definido como uma reação de um sistema orgânico total, com componentes de representação, expressão e motórico-fisiológico." Retomando a concepção de Vygotsky (1991), Camargo (1997) afirma que as emoções passam por um processo de transformação ao longo do desenvolvimento. Nesse processo, as emoções se ligam a outras funções psicológicas, expressando-se junto ou por meio delas. A dimensão simbólica da emoção, portanto, vai se configurando em sua relação com a linguagem, a partir das atividades que o sujeito realiza, sempre mediadas por outros sujeitos e pela cultura (Camargo, 1997; Vygotsky, 1991).

Para González Rey (2003), a emoção pode ser compreendida a partir do conceito de sentido subjetivo, que articula os eventos psicológicos que emergem do desenvolvimento de atividades do sujeito nos diversos contextos em que transita. $\mathrm{O}$ sentido subjetivo se revela, portanto, através de um movimento do sujeito em que os processos simbólicos e as emoções, imbricadas, são acionadas e produzem sentido.

Em suas constantes interações, o sujeito atribui sentido às suas vivências a partir de sua configuração subjetiva, constituída pelos registros de experiências anteriores. Ao 
atribuir novos sentidos subjetivos é capaz de se transformar, alterando também sua própria configuração subjetiva. Dessa forma, o sujeito não se restringe somente a experienciar a subjetividade social, mas também a produz e transforma criativamente, a partir de suas ações.

\section{Método}

Trata-se de uma pesquisa qualitativa exploratória do tipo estudo de caso, que visa identificar o significado e as emoções que as mulheres expressam sobre a articulação das atividades pessoais, profissionais e familiares. A pesquisa foi aprovada pelo Comitê de Ética em Pesquisa da Universidade Tecnológica Federal do Paraná (CEP/UTFPR), sob o $n^{\circ} 413008$.

As quatro participantes da pesquisa foram escolhidas através de amostragem por conveniência, sendo os critérios de elegibilidade: mulheres, mães, com nível de escolaridade superior, desenvolvendo atividade remunerada, recebendo salário superior a cinco salários mínimos, estado civil diverso e com pelo menos um filho vivo. As entrevistas foram realizadas 2016 nos locais de trabalho das participantes que foram identificadas com os nomes fictícios Ártemis, Ariadne, Gaia e Selene, escolhidos por elas.

Ártemis tem 34 anos, é administradora de empresas e no momento da entrevista passava por uma transição profissional: após 12 anos trabalhando na mesma organização, pediu demissão e decidiu rever sua carreira. É casada e tem dois filhos: um menino de sete anos e uma menina de dois anos.

Ariadne tem 35 anos e é casada. Tem um enteado de 15 anos, que não reside com ela, e um filho de cinco anos. É formada em Comércio Exterior e atua na área de exportação, em uma empresa multinacional. O trabalho que desenvolve atualmente envolve contato com as filiais da empresa em diversos países da América Latina, exigindo que trabalhe no estilo home office à noite e nos finais de semana.

Gaia tem 35 anos, é casada e mãe de um menino de seis anos. Formou-se em Economia, fez mestrado e durante o curso identificou-se com a docência. Ao concluir o mestrado ingressou por concurso em uma universidade pública, como economista; 
paralelamente, iniciou como docente em uma faculdade particular. Posteriormente, ingressou como docente concursada na mesma organização em que trabalha como economista, abandonando o emprego na faculdade privada. Atualmente tem dois vínculos públicos de trabalho.

Selene tem 50 anos e é psicóloga, embora não atue nesta área. É funcionária pública federal há 25 anos, como assistente em administração, trabalhando 30 horas semanais. Teve uma relação conjugal estável por dez anos, que terminou há cinco anos; desde então, permanece sozinha. Tem um filho de treze anos.

Utilizou-se a produção fotográfica e a narrativa de quatro mulheres, a partir da consigna "fotografe a sua experiência cotidiana de ser mulher e articule as diversas atividades que você desenvolve, nos diferentes espaços sociais em que vive”. As participantes foram convidadas a produzirem cinco fotografias, a partir das quais organizou-se as entrevistas, cujo objetivo era contextualizar as imagens que explicitaram a experiência subjetiva proposta na consigna, bem como ampliar a compreensão das vivências subjetivas retratadas nas imagens produzidas. $\mathrm{O}$ foco de análise deste estudo não estava dirigido à produção fotográfica em si, mas sim à narrativa da fotógrafa sobre seus conteúdos em cada imagem. Desse modo, utilizou-se a produção fotográfica como uma mediação promotora de significados, e não como um produto a ser analisado.

Inicialmente realizou-se um contato telefônico com as participantes, expondo brevemente o objetivo da pesquisa e agendando um encontro, no qual foi formalizado o convite e explicada a estrutura da pesquisa. Foi apresentada a consigna e solicitada a produção de cinco imagens em um mês. Foram esclarecidas as dúvidas e questões éticas, e assinado o termo de consentimento livre e esclarecido. As imagens foram produzidas por aparelhos digitais das próprias participantes, armazenadas digitalmente e posteriormente enviadas para a pesquisadora. Conforme a produção e o envio das fotografias, a pesquisadora providenciou a revelação das imagens e agendou o próximo encontro.

O segundo encontro foi agendado para um mês após o primeiro; no entanto, como algumas participantes levaram mais tempo para produzir as imagens, os encontros foram realizados em um período de até três meses após o segundo encontro. Nesse momento solicitou-se o preenchimento de um formulário, que visava a caracterização dos 
participantes da pesquisa. Foi também realizada uma entrevista aberta, apoiada nas imagens produzidas, visando a contextualização das fotografias pela produtora e a constituição de uma narrativa sobre ela em relação à consigna original.

As imagens reveladas foram reunidas, formando um conjunto de fotografias. Cada participante escolheu as fotos a ser apresentadas. Explorou-se o conteúdo das imagens, em relação à consigna inicial. A cada foto escolhida, questionou-se a motivação para aquela produção, quais os significados dos elementos retratados e se a imagem tinha uma história. Após a narrativa da última foto, indagou-se que história aquele conjunto de imagens contaram. Finalizou-se indagando sobre a experiência vivenciada durante todo o processo. As entrevistas foram gravadas em aparelho de áudio digital e transcritas pela pesquisadora.

Inicialmente foram organizados os dados de caracterização dos sujeitos da pesquisa, coletados na entrevista estruturada; em seguida, efetuou-se a análise interpretativa do conteúdo das narrativas produzidas na entrevista aberta mediada pelo ensaio fotográfico. A produção imagética e as narrativas foram sintetizadas de forma a apresentar um recorte do conteúdo do material em relação aos objetivos da pesquisa, utilizando-se a técnica de análise de conteúdo (Bardin, 2011), a partir da qual realizou-se a separação e isolamento de cada unidade significativa em relação ao fenômeno investigado. As unidades de análise foram extraídas do texto considerando emoções desencadeadas e relevância para a compreensão do objetivo da pesquisa. O processo de categorização das unidades de análise destacadas foi realizado através de comparações entre as unidades definidas na fase inicial da análise.

\section{Resultados}

\section{Ártemis}

Os espaços sociais registrados por Ártemis foram a família, constituída ao se casar, a família de origem e o trabalho. As categorias que emergiram de sua análise de dados foram: o sentido subjetivo de maternidade; o significado da família no processo de articular atividades; sentido subjetivo de trabalho e sentido subjetivo de articular atividades. Em seu ensaio fotográfico, predominou a figuração de pessoas, entre elas 
membros de sua família de origem, seus filhos, marido e colegas de trabalho da instituição da qual se desligou.

A categoria maternidade revela a necessidade da entrevistada de vivenciar a maternidade como um papel exclusivo e inerente a ela. Seu sentido subjetivo de maternidade é impregnado de vozes sociais que ditam modelos e condições ideais para que a mulher se revele uma boa mãe. A escolha voluntária pela maternidade é subjetivada como exigência de ser uma mãe irrepreensível. O sentido subjetivo da maternidade está relacionado ao exercício do cuidado, que associa afeto à presença física.

A categoria "significado da família no processo de articular diversas atividades" evidencia a subjetivação da família como um importante elemento de troca afetiva, de motivação para sua atuação e conquistas nos diversos espaços sociais nos quais atua. Caracteriza-se como um espaço estruturante, impregnado de significações que permeiam sua articulação de atividades nos outros espaços sociais, e no qual ela desempenha papéis fundamentais.

A categoria "sentido subjetivo da articulação de atividades" revela a percepção de falta de tempo pela entrevistada. A percepção da quantidade e possibilidades de uso do tempo é um aspecto central em sua vivência subjetiva de desempenho de diferentes atividades na esfera familiar e profissional.

\section{Ariadne}

Dos dados fornecidos por Ariadne, emergiram as categorias sentido subjetivo de trabalho; sentido subjetivo de maternidade; sentido subjetivo de articular atividades.

O sentido subjetivo do trabalho expressa os sentidos singulares de trabalho e as necessidades e motivos que configuram sua identidade profissional, em suas vivências no espaço social do trabalho. Esta categoria foi retratada por meio de duas fotografias: a imagem de um cartaz de planejamento com post-its e o registro de um certificado de formação.

A categoria maternidade foi retratada pela imagem do filho lendo um livro infantil, expressando os sentidos que produz ao vivenciar esta experiência e realizar as 
atividades que ela demanda. A maternidade é expressa como uma escolha consciente, acompanhada pela decisão de não abdicar de sua atividade profissional.

A categoria sentido subjetivo da articulação de atividades foi retratada pela fotografia de um sanduíche e um estojo de maquiagem no banco de seu carro. $\mathrm{O}$ discurso acerca da imagem revela a história de uma mulher que, para conseguir realizar todas as tarefas dos contextos pessoal, familiar e profissional, utiliza estratégias de sobreposição de atividades. A autorregulação temporal da vida cotidiana aparece como um elemento central para a articulação de suas atividades, e o tempo é percebido como um recurso insuficiente.

O tempo para si mesma foi retratado em uma fotografia que registra a participante no cabeleireiro. Seu discurso revela a dificuldade em estabelecer um espaço para atividades de lazer e de relaxamento; seu tempo de lazer dela aparece relacionado sempre ao outro, no atendimento das situações familiares com o filho e o marido.

\section{Gaia}

Gaia realizou o registro fotográfico de objetos que representam diversas atividades desempenhadas por ela. A análise dos dados permitiu a identificação de três categorias: sentido subjetivo do trabalho; sentido subjetivo da articulação de atividades e sentido subjetivo da maternidade.

A fotografia que simboliza o sentido subjetivo do trabalho mostra uma sala com cadeiras, um tablado e um quadro negro. Gaia conta que as escolhas do início de sua carreira profissional relacionavam-se não com sua realização pessoal, mas com o atendimento às necessidades financeiras, gerando o sentimento de segurança através da estabilidade no emprego. Seu foco não reside em reduzir a jornada de trabalho, mas em buscar outro tipo de ocupação profissional que considere pessoalmente mais satisfatória. Gaia mantém uma jornada tripla de trabalho, necessária para sua segurança financeira, porém considerada como elemento de sobrecarga, estresse e desgaste.

A articulação das atividades pessoais, profissionais e familiares foi retratada em três fotografias. A despensa de sua casa indica os aspectos da articulação com os quais menos se identifica. Os carrinhos do filho representam a organização do tempo e logística, e o computador simboliza as atividades profissionais desenvolvidas no ambiente 
doméstico, em home office, dificultando o estabelecimento de fronteiras de tempo e espaço entre a vida familiar e profisssional.

Em relação à vida familiar, o tempo para a relação conjugal é insuficiente, predominando o exercício das funções parentais, o que acarreta dificuldades ao estabelecimento da relação homem-mulher. Gaia relata que o cônjuge assume as responsabilidades parentais de forma parcial, indicando que é dela a responsabilidade pela organização e manutenção da rotina do filho. A discrepância na distribuição das responsabilidades familiares entre ela e o cônjuge gera sentimentos de cansaço físico e irritação.

$\mathrm{Na}$ categoria maternidade, Gaia legitimando outros interesses e motivações, indicando que sua identidade não se resume somente à maternidade, associando a dedicação integral à família à privação de estímulos intelectuais. Revela, no entanto, sentimentos de ambivalência entre a maternidade e a realização profissional; embora permaneça buscando realização pessoal em outros contextos além do familiar, na maior parte das narrativas em que se refere à maternidade, relata culpa e sentimentos de insuficiência.

\section{Selene}

A produção fotográfica de Selene referiu-se ao filho e ao exercício da maternidade, bem como à sua subjetividade feminina. A análise da narrativa possibilitou a delimitação de três categorias: sentido subjetivo de maternidade; subjetividade feminina e sentido subjetivo da articulação de atividades.

A fotografia da participante e sua mãe retrata a categoria sentido subjetivo da maternidade. Suas narrativas revelam a importância da mãe em sua configuração subjetiva de maternidade. Selene admite as diferenças entre a geração atual e a de sua mãe, reconhecendo a heterogeneidade de papéis e as conquistas recentes das mulheres; no entanto, afirma acreditar que ainda hoje a identidade da mulher está condicionada à maternidade.

A subjetividade feminina é revelada pelas narrativas que representam o processo de constituição subjetiva da mulher. Selene apresenta representações da mulher enquanto mãe e também da mulher incompleta, expressando dificuldade em reconhecer-se como 
mulher pelo fato de não ter um parceiro. É mobilizada pela experiência subjetiva da feminilidade, reconhecida para ela como vinculada ao relacionamento homem-mulher.

Uma das fotografias produzidas por Selene retrata Freud, indicado por Selene como uma figura importante em sua concepção do que é ser mulher. Ressalta a influência da mãe em sua história de vida, indicando que a necessidade de ser independente advém da forma como sua mãe, insatisfeita com a própria dependência, doutrinou as filhas mulheres.

A categoria sentido subjetivo da articulação de atividades refere-se à percepção da mulher sobre as atividades que ela articula. Esta categoria é evidenciada na imagem registrada por seu filho, a pedido de Selene, em que é retratada dirigindo, levando o filho para a escola. Sua articulação de atividades envolve a maternidade e a esfera profissional e não indica a existência de conflitos, referindo-se mais à sobreposição de tarefas do que efetivamente a um sentimento de cansaço e sobrecarga. Destaca-se a valorização da maternidade como elemento subjetivo mais significativo na experiência de articulação de atividades de Selene. O sentido subjetivo do trabalho relaciona-se apenas à independência financeira, e não ao reconhecimento ou desenvolvimento pessoal ou profissional.

\section{Discussão}

Conforme os procedimentos metodológicos dessa pesquisa, a fotografia foi utilizada como um instrumento de mediação, com o objetivo de estimular a produção de zonas de sentido e a construção de significados sobre a prática pessoal das entrevistadas, em relação à articulação de atividades profissionais, pessoais e familiares.

As fotografias indicavam, de forma direta ou indireta, pessoas significativas na trajetória das participantes. Todas as entrevistadas retrataram os filhos, e metade delas registrou a família constituída pelo casamento e a família de origem. Uma participante retratou o cônjuge. Em suas produções fotográficas, a fotografia foi utilizada como ilustração de suas trajetórias de vida, representando suas experiências de ambiguidade em relação à articulação de atividades. A narrativa das entrevistadas sobre a articulação de 
atividades revelou temas individuais e também comuns a todas as entrevistadas.

Todas as participantes relataram a existência de conflitos em relação aos padrões sociais de excelência de maternidade, que idealizam o papel materno e estabelecem um protagonismo da mãe na educação dos filhos. O exercício da maternidade foi relatado de forma a simbolizar a essência feminina, algo que seria biologicamente determinado e inerente à mulher. Ferreira e Nogueira (2013) abordam a naturalização da representação social da mulher, por meio da qual se acredita que "as diferenças entre os gêneros são decorrentes de alguma característica inata que deixa mulheres e homens diferentes entre si” (Ferreira e Nogueira, 2013, p. 407). Dessa forma, a narrativa das mulheres acerca da maternidade oscilou entre reproduzir vozes sociais, ditando modelos e condições ideais para a maternidade, e configurações singulares de sentidos subjetivos, que permitiram questionar o modelo vigente.

Nos relatos de Ártemis, a família apresenta o sentido subjetivo de motivação e realização. A família é o núcleo de organização e de articulação de suas atividades, e a satisfação em outros espaços vitais é mediada pela centralidade dos papéis de mãe e esposa.

Em relação aos sentimentos e emoções vivenciados na articulação de atividades, é possível identificar sofrimento, cobrança, culpa e cansaço, indicando seu desgaste ao conciliar a realização das diversas atividades. Percebe-se que sua identidade feminina foi absorvida pela identidade materna, gerando ansiedade, sofrimento e certa alienação de si mesma. O sentimento de culpa parece emergir exclusivamente da própria entrevistada, não havendo indicações de cobrança na realização de suas atividades por parte dos filhos.

O trabalho é considerado uma atividade importante, que tem o sentido subjetivo de trazer realização, afirmação social e econômica, ao mesmo em que é subjetivado como atividade que, ao ser realizada, rouba tempo da vida em família. A articulação de atividades nos espaços de trabalho e familiar é vivenciada como um campo permeado de tensões, no qual ela subjetiva a importância do trabalho remunerado e as necessidades de afeto e cuidado da família.

As produções discursivas de Ariadne revelam que sua subjetividade individual é fortemente relacionada aos elementos de sentido da atividade profissional; percebe-se a 
subjetivação dos significados historicamente produzidos pela instituição em que trabalhava, incorporando-os à sua subjetividade individual. $\mathrm{O}$ trabalho confere significado à sua existência e permite sua realização pessoal, sendo subjetivado como elemento regulador de sua autoestima, configurando-se como um instrumento para alcançar a autonomia e a autoafirmação.

Os relatos de Ariadne indicam assimetrias na divisão de tarefas e responsabilidades entre o casal, interferindo diretamente sobre o tempo disponível para a articulação de suas atividades. De forma ambivalente, foram identificadas tanto práticas pautadas em valores tradicionais de gênero como outras que expressavam valores mais igualitários. De acordo com Perrot (1988), Aguiar (1997) e Priore (2004), ao longo da história esse padrão tradicional tem sido dominante no tempo e no espaço e praticamente universal, evidenciando relações de gênero marcadas pela divisão sexual do trabalho, na qual há uma divisão de atribuições assimetricamente valorizadas e os homens assumem a posição dominante. Dessa forma, corroborando com os autores, as narrativas de Ártemis indicaram que a dinâmica de divisão de tarefas entre o casal é um fator que interfere na forma como ela articula suas atividades, agravando a necessidade de disciplinamento temporal para cumprir todas as tarefas implicadas na articulação.

$\mathrm{Na}$ análise das falas de Gaia, percebe-se que a segurança financeira propiciada pelo trabalho como economista lhe cobra um preço simbólico: insatisfação, frustração e sofrimento. Seu discurso indica que sua configuração subjetiva de trabalhadora é fortemente marcada pela insegurança financeira, vivenciada no período da adolescência. Sua história de vida é marcada por situações nas quais as dificuldades financeiras foram subjetivadas como elementos geradores de sofrimento, levando-a a conduzir sua trajetória profissional atual no sentido de assegurar a autonomia financeira.

Percebe-se, em Gaia, um discurso contraditório em relação às expectativas da divisão igualitária de tarefas entre o casal. Ao mesmo tempo em que expressa o desejo de que seu marido assuma uma posição mais ativa e autônoma nas atividades domésticas e familiares, revela acreditar que ele não é capaz de desempenhar adequadamente essas tarefas. Dessa forma, Gaia acaba por reforçar o papel secundário do cônjuge em relação na realização das tarefas da casa e com o filho, valorizando uma identidade feminina que se define no exercício das funções de esposa e mãe, mediando suas expectativas conjugais por esses valores. 
Em relação às narrativas produzidas por Selene, enfatiza-se sua opção pela maternidade, bem como as experiências e concepções de maternidade de sua mãe. Todos os relatos em relação à maternidade vinculam-se, direta ou indiretamente, à sua mãe. Retomando o conceito de naturalização das funções femininas (Ferreira e Nogueira, 2013), há a indicação de que Selene internalizou e configurou subjetivamente os valores e normas patriarcais vigentes na época em que sua mãe vivenciou a maternidade. A escolha da imagem de Freud como representação da feminilidade reforça sua relação com a mãe e pode indicar também, em sua configuração de sentidos subjetivos, a existência de uma concepção de mulher incompleta, que ficou explicitado na sua fala de só atingir a completude ao se relacionar com um homem.

De forma geral, a análise dos discursos relacionados à articulação de atividades das participantes indica a produção de significados relacionados à família, ao trabalho, à busca da feminilidade e à diminuição do investimento na dimensão pessoal de suas vidas. A configuração desses significados interfere sobre suas escolhas na prática de articular atividades, levando à busca de atividades profissionais que permitam a manutenção de sua função de cuidadora familiar. Tal opção, porém, gera desgaste pelo exercício das atividades profissionais, domésticas e maternas, agravada pela sobrecarga da distribuição desigual das tarefas com o cônjuge. Em decorrência desse quadro, emergem o sofrimento, o cansaço e o desgaste, além de sentimentos de culpa pela ausência do convívio familiar.

É importante entender que a articulação das atividades dessas mulheres insere-se no contexto político, econômico, cultural e ideológico da sociedade da qual fazem parte. Nesse sentido, a constituição do sujeito está imbricada com seu contexto histórico e cultural. A dimensão sociocultural do desenvolvimento humano só pode ser compreendida por meio das vivências estruturadas e significadas pelo sujeito em seu grupo cultural. Como define Sartre (2013), o homem deve ser concebido não como indivíduo, mas enquanto universal singular: "universal pela universalidade singular da história humana, singular pela singularidade universalizante de seus projetos, ele exige ser estudado a um só tempo pelas duas pontas" (Sartre, 2013, p. 101). Dessa forma, nenhum fenômeno psicológico existe independentemente do contexto histórico, cultural e social; a subjetividade, portanto, não é estanque, mais depende das atividades e posições do sujeito, das interpretações conflitantes das experiências, das localizações sociais, das histórias dos sujeitos, de suas necessidades e desejos (González Rey, 2003). Cada sujeito 
subjetiva sua realidade de forma particular, constituindo continuamente significados culturais e sociais através das práticas que vivencia.

Percebe-se que a prática de articular atividades das participantes da pesquisa é permeada pelas formas como elas significam e subjetivam suas realidades, expressando as relações que estabelecem com os espaços sociais em que transitam, suas posições dentro desse contexto, a amplitude de suas participações e as influências que exercem nesses espaços. Dessa forma, o conceito de prática é fundamental para a compreensão da articulação das atividades pessoais, profissionais e familiares. Observou-se que todas as entrevistadas estão inseridas em práticas sociais complexas, que as transcendem e demandam a elaboração de caminhos e opções de desenvolvimento.

Evidenciou-se que a prática de articular atividades das participantes da pesquisa é permeada por um alto grau de exigência no exercício de suas funções profissionais, domésticas e maternas. A busca pela conciliação desses papeis de forma exemplar as leva a vivenciar situações ambivalentes pois, mesmo ao ingressarem no mundo do trabalho, não abdicaram das prerrogativas e regras patriarcais tradicionais, as quais definem as atribuições de uma "boa dona de casa" e uma "boa mãe". A sociedade contemporânea reforça a crença de que a realização e reconhecimento social dependem do sucesso profissional e familiar, exigindo que a mulher precisa seja, ao mesmo tempo, bemsucedida profissionalmente, mãe e cuidadora exemplar.

Constata-se, nos relatos das participantes, a sobreposição de tarefas profissionais, domésticas e maternas, com divisão desigual entre os cônjuges. O fato de a mulher ter que assumir maior quantidade de tarefas do que seu parceiro tem sido constatado historicamente e é fruto do padrão histórico de divisão sexual do trabalho. De acordo com esse padrão, há uma divisão de tarefas assimetricamente valorizadas; enquanto os homens assumem a posição dominante, realizando atividades socialmente valorizadas na esfera pública, as mulheres se tornaram responsáveis pela reprodução e pelas tarefas domésticas (Perrot, 1988; Aguiar, 1997; Priore, 2004).

Percebe-se que as mulheres participantes da pesquisa estão marcadas pela subjetividade social dos espaços nos quais atuam. Sua constituição subjetiva as constitui para serem mães, levando à crença de que são insubstituíveis na vida de seus filhos, aos quais devem se dedicar com esmero. Nesse sentido, ser mulher se confunde com ser mãe. 
Sobre o biológico, portanto, recaem significados culturais, sociais e históricos, que vinculam a mulher ao exercício da maternidade, permeando as práticas sociais de homens e mulheres até os dias atuais (Badinter, 2011; Priore, 2013).

\section{Considerações Finais}

Buscou-se a identificação e a compreensão da realidade singular de cada uma das mulheres participantes da pesquisa, no processo de articular atividades na vida pessoal, familiar e profissional. O intuito da pesquisa não é generalizar os fatos para retratar uma verdade específica, pronta e acabada; ao contrário, o estudo foi orientado pela possibilidade da criação de novas zonas de sentido em relação aos significados, sentidos e emoções que as mulheres expressam sobre a articulação de suas atividades. Pautado pelo posicionamento delimitado teoricamente, intentou-se ampliar a discussão sobre os temas que emergiram nas narrativas das entrevistadas.

$\mathrm{O}$ estudo revelou que as mulheres participantes da pesquisa integram um espaço social que demanda constantemente a combinação de novas soluções, implicando na tomada de decisões entre opções ambivalentes. Este achado é corroborado por Tourraine (2007), ao afirmar que o cenário social atual se modifica constantemente. Nesse contexto, em que as subjetividades também são mutáveis e múltiplas, a ambivalência vivenciada pela mulher contemporânea caracteriza-se como uma forma de resolução de problemas inovadora, porém geradora de frustrações e incertezas (Tourraine, 2007).

Dessa forma, considerando as complexas redes de significação em que essas mulheres estão inseridas, constata-se que a articulação de atividades profissionais, pessoais e familiares é caracterizada por uma ambivalência. No contexto público, conseguem ocupar posições profissionais promissoras e expressam sentidos subjetivos de igualdade em relação aos homens, no que diz respeito ao desempenho, dedicação e competências; revelam, apesar disso, estar conscientes das desvantagens na competição com o gênero masculino, pelo fato de possuírem carga maior de trabalho, incluindo os cuidados da casa, dos fillhos e da família. No âmbito privado, no que tange à divisão das tarefas domésticas e ao cuidado dos filhos, as práticas das participantes da pesquisa são marcadas pelo conservadorismo. As vivências ambivalentes entre maternidade e trabalho, bem como o alto nível de exigência quanto ao desempenho familiar e profissional, 
permeiam a vida de todas as entrevistadas e levam à percepção da falta de tempo para si mesmas, gerando sentimentos de sobrecarga, cansaço, sofrimento e culpa.

Esta pesquisa revela as dimensões naturalizantes implicadas na vida das mulheres entrevistadas, evidenciando a produção de sentidos subjetivos ambivalentes; a articulação das atividades, dessa forma, é caracterizada como um processo árduo, marcado pelo desgaste e sofrimento. Espera-se que as reflexões suscitadas a partir dessa pesquisa constituam-se como instrumentos de produção de novas zonas de significação, promovendo novas formas de subjetivar as relações que envolvem a articulação das atividades femininas, revendo as concepções tradicionais hegemônicas sobre gênero, crenças e valores patriarcais, levando a construção de novas práticas sociais.

\section{Referências}

Aguiar, N. (1997). Perspectivas feministas e o conceito de patriarcado na sociologia clássica e no pensamento sociopolítico brasileiro. In N. Aguiar (Org.), Gênero e ciências humanas: desafio às ciências desde a perspectiva das mulheres (Vol.5, pp.161191). Rio de Janeiro: Rosa dos Tempos.

Badinter, E. (2011). O Conflito: A mulher e a Mãe. (V. L. dos Reis, Trad.), Rio de Janeiro: Record.

Bardin, L. (2011). Análise de conteúdo. (L. de A. Reto \& A. Pinheiro, Trad.). São Paulo: Edições 70.

Bosco, A. P. (2009). Entre a essência e a construção: experiências cotidianas do feminismo a partir da produção fotográfica de jovens mulheres paulistanas. Dissertação de Mestrado, Programa de Pós-Graduação em Psicologia, Universidade de São Paulo, São Paulo.

Bulgacov, Y. L. M., de Camargo, D., Canopf, L., de Matos, R. D., \& Zdepski, F. B. (2014). Contribuições da teoria da atividade para o estudo das organizações. Cadernos EBAPE. BR, 12(3), 648-662.Recuperado de https://doi.org/10.1590/1679-39519019 
Camargo, D. (1997). As emoções no processo de aprendizagem. Tese de Doutorado Não-Publicada, Programa de Pós-Graduação em Psicologia Social, Pontifícia Universidade Católica de São Paulo, São Paulo.

Ferreira, J. M., \& Nogueira, E. E. S. (2013). Mulheres e Suas Histórias: Razão, Sensibilidade e Subjetividade no Empreendedorismo Feminino. RAC-Revista de Administração Contemporânea, 17(4), 398-417.Recuperado de https://doi.org/10.1590/S1415-65552013000400002

González Rey, F.G. (2003). Sujeito e subjetividade: uma aproximação históricocultural. São Paulo: Pioneira Thomson Learning.

González Rey, F.G. (2012). O social na psicologia e a psicologia social. (3a ed.) Petrópolis: Vozes.

IBGE - Instituto Brasileiro de Geografia e Estatísitca (2012). Pesquisa mensal de emprego - PME. Mulher no mercado de trabalho: perguntas e Respostas.08 de março de 2012.. Recuperado de:

$<$ http://www.observatoriodegenero.gov.br/menu/noticias/mulher-mercado-trabalhoperg-resp-2012.pdf > . Data do acesso 27 nov. 2014.(DOI inexistente)

Leontiev, A. N. (1978). Atividad, consciência y personalidad. Buenos Aires: Ciencias del Hombre.

Mestres (2012).) : Estudos da demografia da base técnico-cientifica brasileira. Centro de Gestão e Estudos Estratégicos (CGEE) Brasília, DF. Recuperado de https://www.cgee.org.br/documents/10195/734063/Mestres2012\%28corrigido_18jun 2013\%29 9536.pdf

Perrot, M. (1988). Os excluídos da História: operários, mulheres, prisioneiros. (4. ed.) Rio de Janeiro: Paz e Terra.

Priore, M. (2004). História das mulheres no Brasil. (7. ed.) São Paulo: Contexto. Priore, M. (2013). Histórias e Conversas de Mulher. São Paulo: Planeta. Sartre, J. P. (2013). O idiota da família.São Paulo: L\&PM. 
Touraine, A. (2007). O mundo das mulheres. São Paulo: Vozes.

Vygotsky, L.S. (1991). Obras Escogidas. Tomo I: El significado histórico de la crisis de la psicología. Uma investigación metodológica. Madrid: Visor.

Vygotsky, L. S. (1994) A formação social da mente: o desenvolvimento dos processos psicológicos superiores. 5. ed. São Paulo: Martins Fontes.

World Economic Forum. (2014) Recuperado em 27 de novembro de 2014, de http://reports.weforum.org/global-gender-gaprepor2014/economies/\#economy=BRA. 